\title{
Five level inverter for renewable power
}

\section{generation system}

\author{
Mahammed Sameer m Attar ${ }^{1}$, K V Shettigar ${ }^{2}$ \\ PG Scholar, Department of EEE, NMAMIT, Nitte, Karnataka, India ${ }^{1}$ \\ Associate Professor, Department of EEE, NMAMIT, Nitte, Karnataka, India ${ }^{2}$
}

\begin{abstract}
Reformations in electricity sector along with various renewable energy promotion policies has increased the importance of small grid connected photovoltaic (PV) systems utilizing single-stage single-phase inverters. To improve the performance multilevel inverter are preferred over two levels. This paper proposes a single-stage five level inverter for grid connected (PV) system. The output current of the inverter can be adjusted according to the voltage of the photovoltaic (PV) array. This control scheme is based on SPWM topology. Schemes based on SPWM which do not require the service of a phase locked loop for interfacing the inverter to the grid are increasingly being employed for such applications. Performance evaluation of the five-level inverter is done on Matlab platform. The viability of the proposed scheme is confirmed by performing simulation and results validation.
\end{abstract}

Keywords: Five level inverter, Cascaded H-bridge inverter, PWM, Solar PV array.

\section{INTRODUCTION}

The Demand for renewable energy has increased significantly over the years because of shortage of fossil fuels and greenhouse effect. Among various types of renewable energy sources, solar energy and wind energy have become very popular and demanding due to advancement in power electronics techniques. Photovoltaic (PV) sources are used today in many applications as they have the advantages of being maintenance and pollution free. Solar electric energy demand has grown consistently by $20 \%$ to $25 \%$ per annum over the past 20 years, which is mainly due to the decreasing costs and prices. This decline has been driven by the following factors

1) An efficiency of solar cells is more

2) improvements in Manufacturing technology

3) scale of Economies

PV inverter, which is the heart of a PV system, is used to convert dc power obtained from PV modules into ac power to be fed into the grid. Improving the output waveform of the inverter reduces its respective harmonic content and, hence, the size of the filter used and the level of Electromagnetic Interference (EMI) generated by switching operation of the inverter. In recent years, multilevel inverters have become more attractive for researchers and manufacturers due to their advantages over conventional three level PWM inverters. They offer improved output waveforms, smaller filter size and lower EMI, lower Total Harmonic Distortion (THD).

The three common topologies for multilevel inverters are as follows:

1) Diode clamped (neutral clamped)

2) Capacitor clamped (flying capacitors)

3) Cascaded H-bridge inverter. 
NMAM Institute of Technology, Nitte

Vol. 3, Special Issue 2, Month 2016

II. CONFIGURATION OF PROPOSED CASCADED H-BRIDGE FIVE LEVEL INVERTER

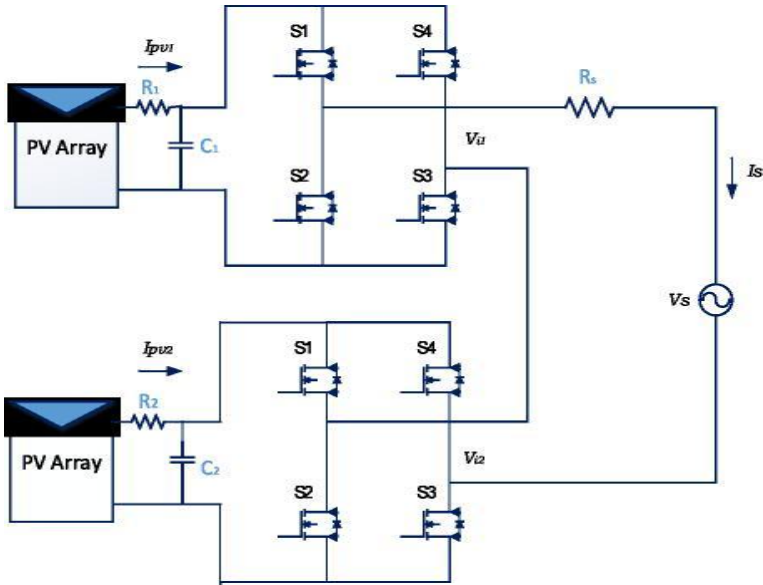

fig. 2 five level topology for grid connected system

\section{SPWM CONTROL TOPOLOGY}

The sinusoidal SPWM is most widely used PWM control method due to many advantages including easy implementation, lower harmonic outputs according to other techniques, and low switching losses. In the SPWM, a sinusoidal reference voltage waveform is compared with a triangular carrier waveform to generate gate signals for the switches of inverter. Several multicarrier techniques have been developed to reduce the THD ratios, based on the classical SPWM with triangular carriers.

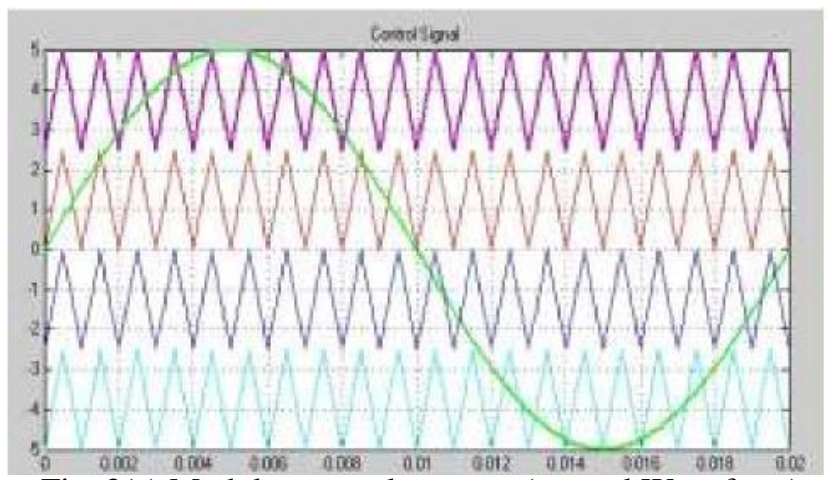

Fig. 3(a) Modular control strategy (control Waveform)

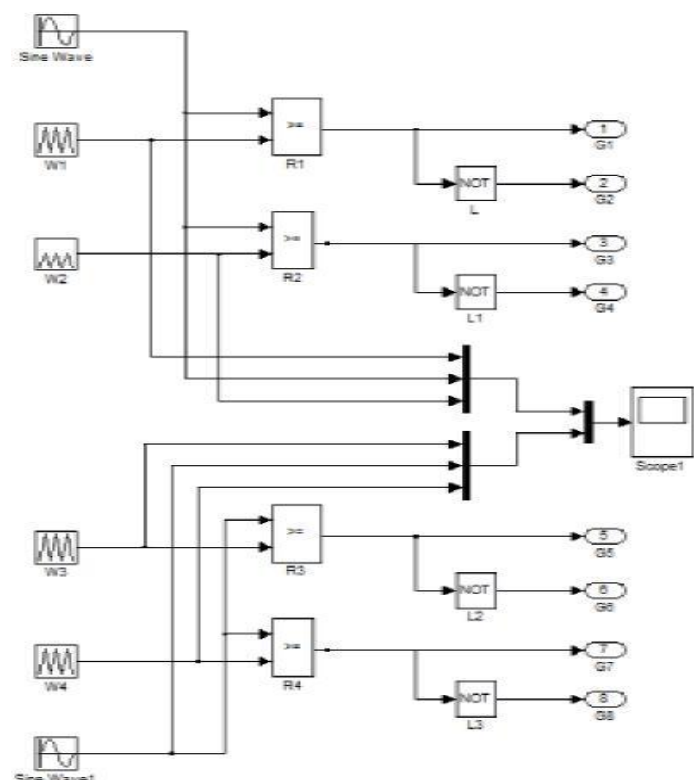

Fig. 3 (b) Modular control strategy (Block diagram) 
In SPWM control, a high frequency triangular carrier signal is compared with a low frequency sinusoidal modulating signal in an analog or logic comparator devices. The frequency of modulating sinusoidal signal defines the desired line voltage frequency at the inverter output. The modulation algorithm has been performed in SPWM modulator block to generate 4 separate SPWM pulses for individual H Bridge.

\section{SIMULATION SETUP}

In order to verify the performance of proposed cascaded H-bridge five level inverter, detailed simulation studies are carried out on MATLAB-Simulink. Simulation model of the proposed system is simulated in Matlab Simulink software as shown in Fig. 4 and modular controller of the proposed system is shown in Fig.3 (a).

According to specification of PV array solar insolation is set at $1000 \mathrm{~W} / \mathrm{m} 2$. At $1000 \mathrm{~W} / \mathrm{m} 2$ insolation, the output of PV array will be 115 Volt which will be fed to cascaded H-bridge inverter. Two individual cascaded H-bridge inverters are used for grid integration. Output of two cascaded H-bridge Inverters is $230 \mathrm{~V}$ AC and will be directly connected to grid utility. This inverter output is controlled by modular control strategy. Two individual modular controllers are used for both inverters. Modularcontroller is shown in Fig. 3(b) IGBT switches for inverter topology. The detail parameters of the inverter chosen for the purpose of simulation and controller are as follows:

Solar Insolation: $1000 \mathrm{~W} / \mathrm{m}^{2}$

Nominal Solar array voltage: 115 Volts

Resistance R1, R2: $1.5 \mathrm{Ohm}, 10 \mathrm{Ohm}$

DC link Capacitor: $2200 \mu \mathrm{f}$

Grid Voltage: 230 Volts

Filter fundamental frequency: $50 \mathrm{~Hz}$

Simulation model of proposed five level inverter fed solar grid connected system is shown in Fig. 4. DC link capacitor $\mathrm{C} 1$ and $\mathrm{C} 2$, resistances $\mathrm{R} 1$ and $\mathrm{R} 2$ is used for interconnection of PV array and Cascaded H-bridge inverters.

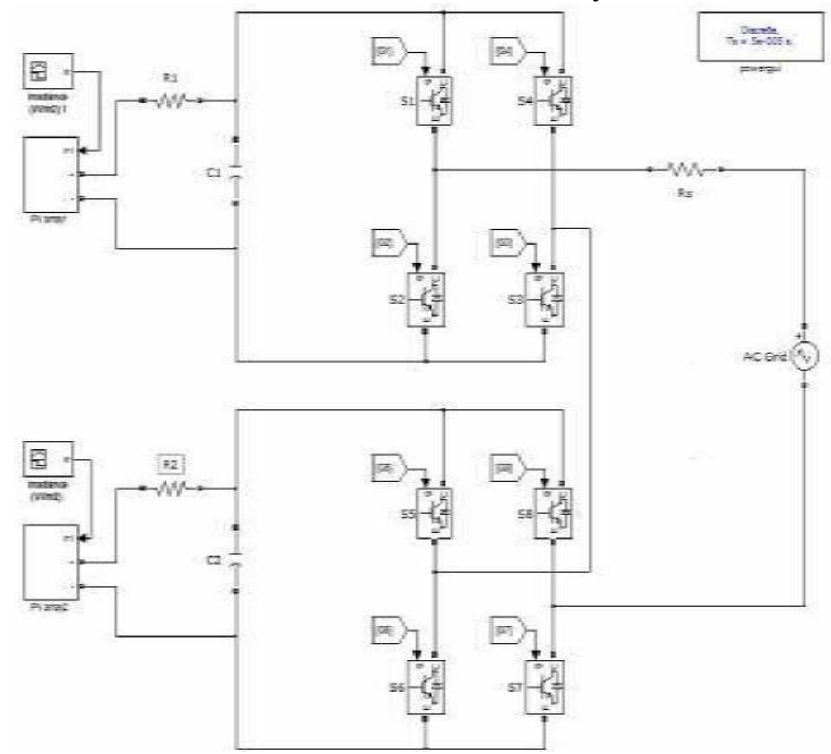

Fig. 4 Simulation model of proposed system

\section{RESULTS AND DISCUSSION}

MATLAB simulation set up of five level inverter is shown in Fig.4. Output PV array is connected to the Inverter and it is directly integrated with DC link Voltage Fig. 4(a) to (d) show the simulated waveforms of the DC link voltage, Output voltage, output current, and AC grid voltage. This DC link voltage shows output of one solar equivalent circuit model. Output voltage and output current of five level inverter is settle down after the 2 to 4 msec is shown in Fig. 4(b) and (c). 
NMAM Institute of Technology, Nitte

Vol. 3, Special Issue 2, Month 2016

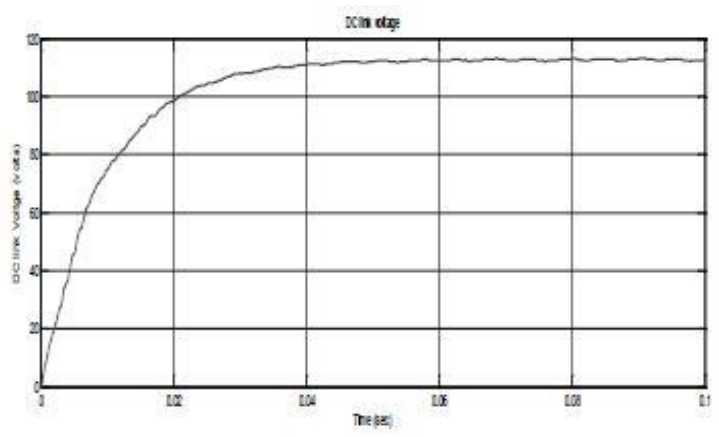

Fig. 4 (a) DC Link Voltage

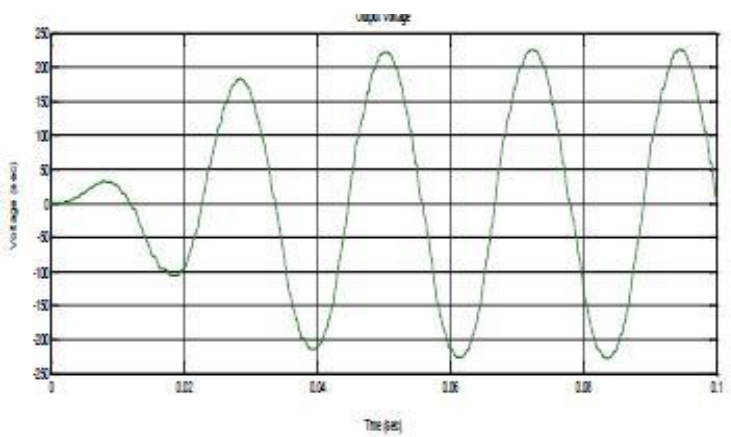

Fig. 4 (c) Output current of Inverter

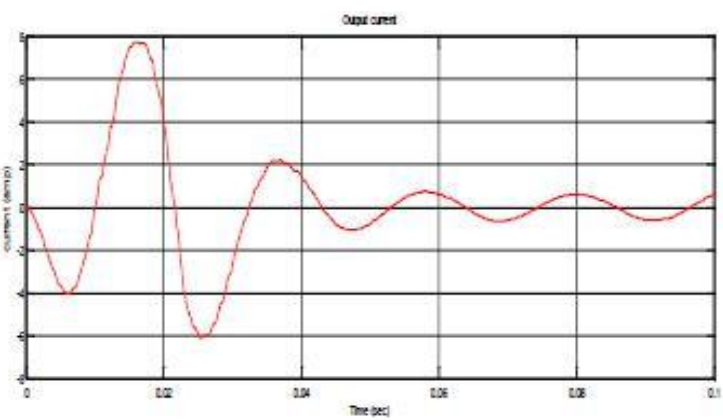

Fig. 4 (d) Grid Voltage

Solar Five level inverter is required 2 to 4 msec for PV grid integration with Single phase supply. This results clearly shows the solar grid integration is based on cascaded H-bridge inverter based on SPWM control technique

\section{CONCLUSION}

In this paper, simplified Single phase cascaded H-bridge Five-level inverter used for solar grid integration application has been presented. The performance Evaluation of the five-level inverter is done on Matlab platform. And comparing its simulated voltage waveform with respect to the conventional single phase cascaded H-bridge inverter. So control strategy based on SPWM topology is very simple technique for grid integration. For solar PV array integrated to grid, only 2 to $4 \mathrm{msec}$ are required. This is follows under the Voltage level and phase angle between voltage and current

\section{REFERENCES}

[1]. K.H.Solangi, M.R.Islam, R.Saidur, N.A.Rahim, and H.Fayaz, A review on global solar energy policy, Renewable Sustainable Energy Rev., vol. 15, no. 4, pp. 2149-2163, May 2011.

[2]. M. Calais, J. Myrzik, T. Spooner, and V. Agelidis, Inverters for single phase grid connected photovoltaic systems ${ }^{2}$ an overview, in Proc. IEEE Power Electron. Spec. Conf., Jun. 2002, pp. 1995-2000.

[3]. IlhamiColak, ErsanKabalci, RamazanBayindi r, Review of multi level voltage source i nverter topologies and control schemes, Energy Conversion and Management of elseveir journal 2010.

[4]. Bailu Xiao, FaeteFilho, Leon M. Tolbert, Single-Phase Cascaded H-Bridge Multilevel Inverter with Nonactive Power Compensation for GridConnected Photovoltaic Generators, IEEE Trans. Ind. Electron, 2013. 